\title{
ORGANIZATIONAL AND LEGAL ASPECTS OF DEVELOPING AND IMPLEMENTING PROSPECTIVE HEAT SUPPLY SCHEMES IN MUNICIPALITIES
}

\author{
Y.G. MUNTS ${ }^{1} \&$ V.A. MUNTS 2 \\ ${ }^{1}$ Department of Control Systems in Power Engineering and Production Plants, Ural Federal University. \\ ${ }^{2}$ Department of Heat Power Engineering and Heat Engineering, Ural Federal University.
}

\begin{abstract}
The paper analyses current legislations that regulate the development and implementation of municipal heat supply systems. A cost-effectiveness analysis of an investment programme model taken for a particular heat supply scheme in a Sverdlovsk regional municipality reveals a certain number of problem areas of organizational and legal nature in the overall heat supply process. Hence, certain ways of amending existing legislations are proposed to improve and streamline the heat supply restructuration process. The paper also presents an algorithm of cooperation for heat supply participants whenever an energy service company enters the scheme as an investment process operator.
\end{abstract}

Keywords: efficiency, energy service contract, heating, investments.

\section{INTRODUCTION}

Heating legislation provides for the development and approval of heating schemes for municipal entities [1].

Whenever a heating scheme is developed for efficiency, it is also necessary to collate a corresponding investment programme.

Requirements for Heating Schemes [2] stipulate that 'proposals to invest in existing facilities or investments to be made by certain organizations are only approved within a heating scheme if there is consent of persons possessing the facilities on the right of ownership or other legal right, or consent of corresponding organizations for implementing the investment projects'.

Hence, if a municipal entity has several private heat suppliers, the administration has to develop an investment programme that would lead to the overall improvement of heating efficiency within the municipality, on the one hand, and one which will not be rejected by the owners (renters) of the heating facilities, on the other. This is a serious problem and it cannot be solved in many real-life situations; to complicate matters, the corresponding legislation does not provide for mandatory organizational arrangements or developments that heating process participants need to follow to realize the scheme mentioned above.

Let us consider an investment programme within a real heating scheme developed by the administration of a small municipal entity in Sverdlovsk region, a town with a population of about 18,000 people distributed among 18 villages. There are two thermal energy suppliers working in the town: private company 'ZAO X' (Close Joint-Stock Company) with 7 gas boiler rooms with the capacity of $41 \mathrm{Gcal} / \mathrm{h}$, and municipal organization $\mathrm{Y}$, which has $12 \mathrm{coal}$ boiler rooms with a total installed capacity of $9.9 \mathrm{Gcal} / \mathrm{h}$ under its economic jurisdiction. Besides the town boiler plants, the municipal organization $\mathrm{Y}$ also administers village coalfired boiler plants. The total number of the village boiler plants therefore amounts to 22 , and the summed installed capacity is $17 \mathrm{Gcal} / \mathrm{h}$. 
Table 1: Summary data on the investment programme.

\begin{tabular}{ll} 
Indicators & Amount \\
\hline Summed investment, thousands of roubles, incl. VAT & $127,986.8$ \\
Boiler rooms of municipal organization Y & 99,162 \\
- heat networks within the working zone of 'ZAO X' & $26,328.3$ \\
- heat networks within the working zone of municipal organization Y & $2,496.5$ \\
Economic benefits, ths. Rbs. a year exc. VAT & 25,569 \\
For 'ZAO X' & 9,446
\end{tabular}

We propose an investment programme within the heating scheme, with the following steps to be taken:

- Disconnecting private housing from central heating, with further transition to individual gas heating. At present, the connected heat load of private residences is $1.6 \mathrm{Gcal} / \mathrm{h}$ only, but this impedes the economic performance of the boiling plants due to significant energy losses in heat networks (during heat transfer to private cutomers);

- Constructing additional heat networks for a load transfer from a number of small ineffective coal boiler plants under the administration of municipal organization $Y$ to underused gas boilers of 'ZAO X'. With the installed capacity of 'ZAO X' boiler plants amounting to $41 \mathrm{Gcal} / \mathrm{h}$, the connected load of the plants' customers will consequently be as little as $30 \mathrm{Gcal} / \mathrm{h}$.

- Constructing heat networks to connect prospective consumers with each new construction. New customers will mostly be connected to the operational zone of 'ZAO X' boiler plants.

The investment necessary and the cost-benefit analysis of the programme are given in Table 1.

\section{COST-PERFORMANCE ANALYSIS OF THE INVESTMENT PROGRAMME}

The real discount rate $r_{\mathrm{p}}$ was calculated by the Fisher equation. The price growth rate for thermal energy, gas and electricity, as well as fixed assets depreciation in the process of construction were taken at the annual level of $i=6 \%$. The interest rate on borrowed assets is taken at $16 \%$ per annum, which reflects real loan rates for Russian commercial banks. The interest rate deductible for profit taxation is taken in accordance with the Tax Code of the Russian Federation, Chapter 25 [3], with the coefficient 1.8 to the official base rate of the Central Bank of Russian Federation, which equals 8.25\%.

Taking into account the assumptions mentioned and assuming that all the investments are being leveraged, we calculate the discount rate in accordance with [4], which makes it $6.63 \%$ per annum. The cost-effectiveness of the investment programme for the proposed heating scheme is to be compliant with the mathematical model based on discounted cash flow valuation, which accounts for such outcome efficiency criteria as NVP (net present value), PBP (payback period) and IRR (internal rate of return). A series of various approaches were considered while modelling the programme: firstly, cost-effectiveness analysis of the programme on the whole, that is cost-effectiveness in terms of increasing the overall efficiency 
of the municipal heating process; followed by cost-effectiveness analysis for different participants of the process - the owners and renters of the systems that generate and transfer thermal energy.

\subsection{Cost-effectiveness of the entire programme}

The cost-effectiveness of the investment programme for the proposed heating scheme was calculated in compliance with a mathematical model based on the valuation of discounted cash flows generated while implementing the project. The payback for the entire programme, without legal and organizational considerations, is represented in Fig. 1. The summary of cost-effectiveness for the investment programme is shown in Table 2.

It is obvious that the programme is cost-effective despite the fact that the summary figures are not very high; for the heat power industry these values are quite acceptable.

In general, the programme can be implemented even if it be leveraged.

\subsection{Current legal and organizational issues concerning the programme}

Data in Table 1 show that economic benefits thus achieved are realized in both of the companies, one of them being private and the other municipal. The value of benefits for the private company is comparable to the value of benefits gained by the municipal company in question.

As concerns the investments, they are supposed to flow into the facilities administered by the municipal company; hence, this company will account for a part of the overall value of benefits produced by the total of all investment.

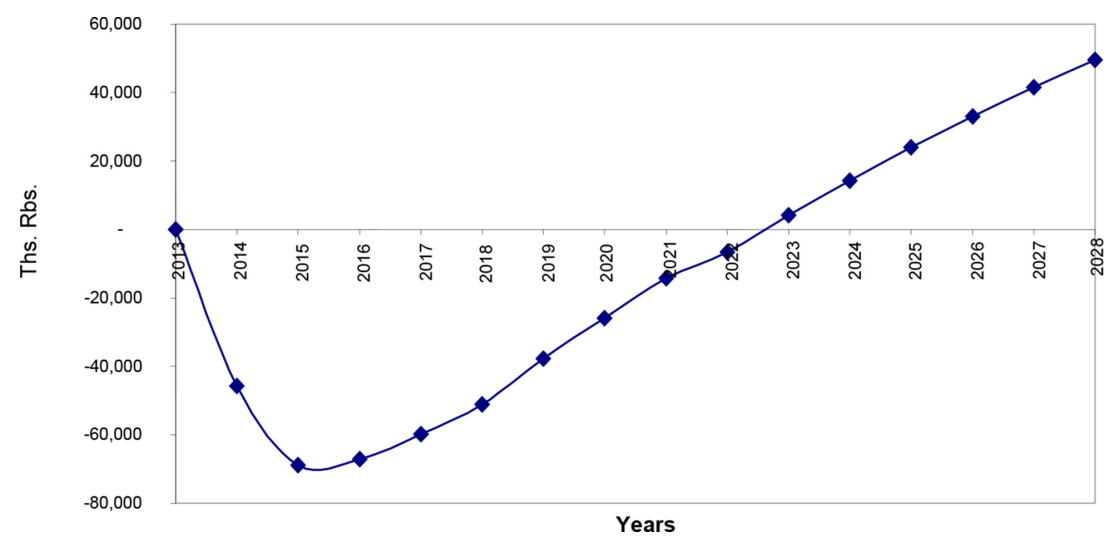

Figure 1: Total net discounted cash flow.

Table 2: Summary of cost-effectiveness for the investment programme.

\begin{tabular}{ll}
\hline Factor & Value \\
\hline Project net present value (NPV) in 2028, ths. Rbs. & 49,552 \\
Payback period (PBP), yrs. & 10 \\
Internal rate of return (IRR), percent per annum & $14.60 \%$ \\
\hline
\end{tabular}


Table 3: Cost-effectiveness of the investment programme for municipal organization Y.

\begin{tabular}{ll}
\hline Factor & Value \\
\hline Project NPV in 2028, ths. Rbs. & $-5,994$ \\
PrTotal net discounted cash flow for municipal organization Y within current & Over 15 \\
legal-organizational scheme programme PBP, yrs. & \\
IRR, percent per annum & $5.57 \%$ \\
\hline
\end{tabular}

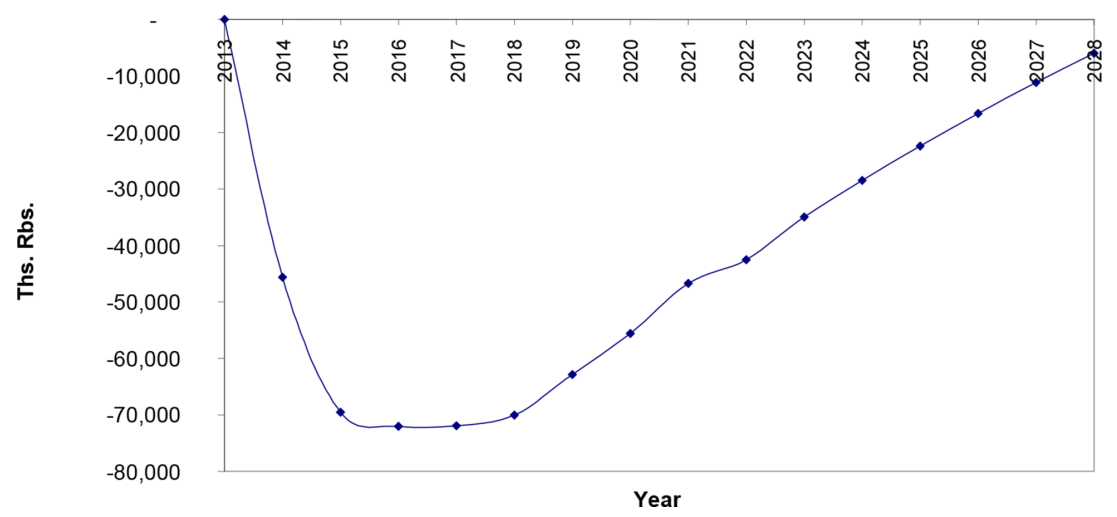

Figure 2: Total net discounted cash flow for Y, MUE with the current legal-organizational scheme.

Figure 2 shows the chart of payback (or of the absence of such) generated by the project for municipal organization $Y$; the chart is drawn on the assumption that all the investment is to be made by that company, with only a part of the expected economic benefit produced, as presented in Table 1.

\section{ACHIEVING PERFORMANCE INDICATORS OF THE HEATING SCHEME IN THE WORKING PROCESS}

\subsection{Modifications to existing contractual relationships}

To balance the situation described above, we suggest that the municipal administration combine their efforts with 'ZAO X' and develop a co-investment scheme. One of the possible ways to realize this is by leasing the heating networks within the operational zone to 'ZAO $\mathrm{X}^{\prime}$ on the condition of co-investing in their development. The investment sum, as Table 1 shows, will amount to 26,328 (thousand roubles, including VAT), with economic benefits for 'ZAO X' going up to 9,446 thousand roubles. This scenario will improve the situation for the municipal enterprise, albeit not very significantly; yet, the programme will generate payback within the period under study (see Fig. 3).

Project performance figures for the two enterprises are shown in Table 4 corresponding to Fig. 3.

This way of implementing the programme is obviously better because all participants are equally involved; however, the aim of a municipal administration is to select a cooperation 


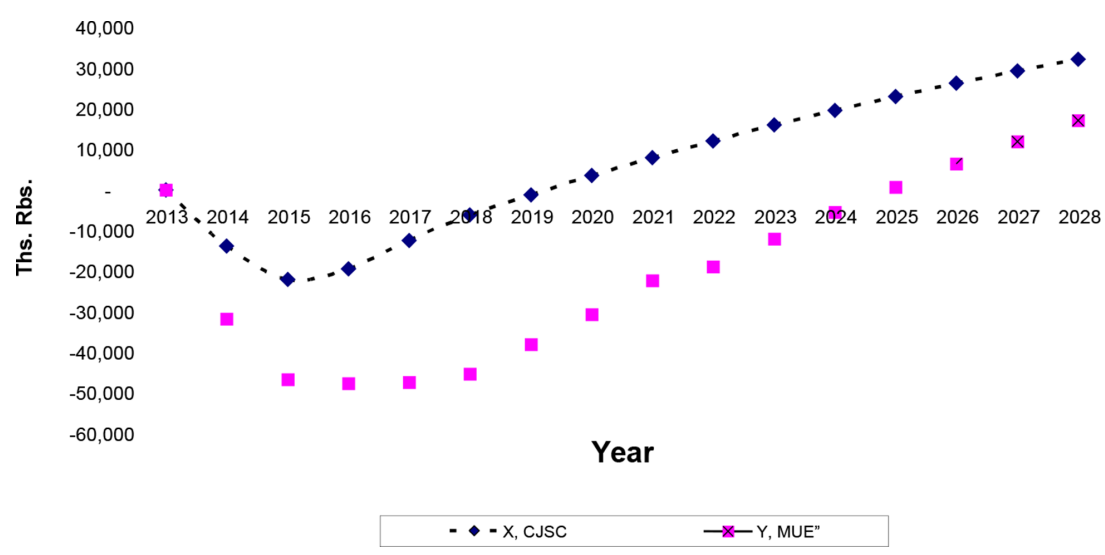

Figure 3: Total net discounted cash flow for ' $\mathrm{ZAO} \mathrm{X}$ ' and municipal organization $\mathrm{Y}$ with a modified legal and organizational scheme.

Table 4: Cost-effectiveness of the investment programme for municipal organization $\mathrm{Y}$ and 'ZAO X' with a modified legal and organizational scheme.

\begin{tabular}{lll}
\hline Factor & Y, MUE & X, CJSC \\
\hline NPV in 2028, ths. Rbs. & 17,177 & 32,192 \\
PBP, yrs. & 11 & 7 \\
IRR, percent per annum & $10.56 \%$ & $23.64 \%$ \\
\hline
\end{tabular}

scheme where project performance indicators for different participants will be equal to the summed indicators of the entire project.

3.2 Introducing an energy service company into the heating scheme as an additional participant of its implementation

In case it is impossible for all participants of the heat supply process to reach an agreement on a new contractual relationship or on changing a leaseholder within the framework of a given legal organizational scheme, the heating scheme discussed above cannot be put into practice.

Besides, as seen above, in this case the economic benefits of the investment programme will be unequal for different participants of the same heating scheme. To equalize the economic indicators and implement the heating scheme with a certain degree of success, we propose taking one more approach. We suggest introducing an additional participant into the scheme, a company that will directly implement the investment programme on the basis of contracting other participants to provide energy services. The company has to be chosen by the municipal administration on a competitive basis according to the current legislation [5].

The subject matter of the municipal contract given by the administration to the company should involve the implementation of the investment programme within the frame of the approved heating scheme; depending on the investment potential of the activities included into the programme, there are various ways for the municipal administration to realize the programme itself, such as: 
- Direct budget funding by awarding the municipal contract for a complex of design and construction-assembly works within the frame of the investment programme;

- Providing municipal guarantees to the energy service company to facilitate loans from commercial banks;

- Controlling the implementation of the programme.

The ownership of the energy service company can be either at the private or state level, as both private and state companies can be provided with budget funding by the budget legislation [6].

Cooperation with other participants of the heating scheme is to be performed by the following algorithm:

First Stage. In accordance with the scheme, the energy service company and the participants of the heat supply process have to conclude the energy service contracts that should stipulate the following terms:

- A list of the investment activities performed by the energy service company in accordance with the investment programme;

- Investment procedures and scheduling for the same;

- Commissioning time T, after which the energy service company is to put newly constructed (or reconstructed) premises and equipment into operation;

- Annual energy savings in physical terms generated by each participant as a result of implementing the investment programme after time $\mathrm{T}$; this is to be calculated separately for each energy source;

- Annual savings payable by each participant to the energy service company as a remuneration for the investment activities performed;

- The duration of the energy service contract calculated on the basis of full return on investment, accounting for capital cost;

- The order of transferring newly created fixed assets into the ownership of a participant.

It should be noted that virtually all these are included into Requirements for Energy Service Contract Terms [7], except for the stipulation that the duration of an energy service contract must correspond to the payback time of investment activities accounting for capital cost (the interest rate on borrowed assets). This condition is vital with regard to the obligation of returning borrowed assets with interest by using the remuneration (savings fraction) accruing to the energy service company from implementing the energy service contract.

Second Stage. The energy service company in cooperation with the municipal administration determines funding sources for the investment programme and holds negotiations and enters into commercial bank loan agreements secured by municipal guarantees; if a project does not bring a return on investment, or if some programme participants are budget organizations, budgetary funds may be provided to fund such investment programmes. In this case, the administration awards a municipal contract to the energy service company for a range of design and construction-assembly works.

The Third Stage. Implementation of investment activities. The administration must control the timing and quality of performance during all stages of construction and reconstruction.

The Fourth Stage. Completion of construction works and achievement of energy saving objectives, return on investment within the deadline pre-determined by the programme. 
It should be noted that when developing a heating scheme, it is obligatory to introduce the section 'Alternative organizational and legal schemes of implementing an investment programme' to ensure a successful realization of the programme. It is recommended that this section discloses actual organizational problems in implementing the investment programme and proposes a legal mechanism to solve these problems within the framework of the current legislation.

\section{CONCLUSIONS}

1. The process of developing a heating scheme and adjusting it for a municipal entity can be made difficult or even impossible when there is a conflict of interest between the participants of the process in question, that is, between the owners or organizations that operate heating plants and networks.

2. To successfully implement the investment programme within a heating scheme, a municipal administration should cooperate with heat supply organizations to introduce and entrench organizational and legal decisions of programme co-investment from various heat supply organizations, whose performance should thereby increase. For example, current contractual relationships within the heating scheme can be modified.

3. Introducing an additional participant into the scheme (an energy service company chosen by the administration on a competitive basis) could become an effective way of realizing a heating scheme. The company is then to perform as an investment programme operator and is to be held responsible for performing all activities and paying back investment. Cooperation with other heating process participants is to be performed on the basis of energy service contracts.

\section{REFERENCES}

[1] Federal Law № 190-FZ “On Heat Supply”. 27 July 2010. Rossiyskaya Gazeta, № 168, 30 July 2010.

[2] Resolution of the Government of the Russian Federation № 154 of February 22, 2012 "On Requirements for Heating Schemes, Procedures for Developing and Approving Them”. Legislation Bulletin of the Russian Federation, № 10, p. 1242, 05 March 2012.

[3] Tax Code of the Russian Federation (part II) № 117-FZ of August 05, 2000. Parlamentskaya Gazeta, № 151-152, 10 August 2000.

[4] Specific Features of Calculating the Cost of Capital and Cash Flow for the Assessment of Russian Companies. /Yu.G. Munts// Science Review, № 1, pp. 364 - 367, 2013.

[5] Federal Law № 44-FZ “On Contract Systems in the Sphere of Procurement of Goods, Works and Services for Provisioning Governmental and Municipal Needs". 05 April 2013. Rossiyskaya Gazeta, № 80, 12 April 2013.

[6] Budget Code of the Russian Federation № 145-FZ of July 31, 1998. Rossiyskaya Gazeta, № 153 - 154, 12 August 1998.

[7] Resolution of the Government of the Russian Federation № 636 of August 18, 2010 "On Requirements for Terms and Conditions of Energy Service Contract and Specifics of Determining the Initial (Maximum) Energy Service Contract Price (Lot Price)". Legislation Bulletin of the Russian Federation, № 34, 23 August, p. 4488, 2010. 